\title{
Repatriation and the RAdical Redistribution of Art
}

\author{
ERICH HATALA MATTHES \\ Department of Philosophy, Wellesley College
}

\begin{abstract}
Museums are home to millions of artworks and cultural artifacts, some of which have made their way to these institutions through unjust means. Some argue that these objects should be repatriated (i.e., returned to their country, culture, or owner of origin). However, these arguments face a series of philosophical challenges. In particular, repatriation, even if justified, is often portrayed as contrary to the aims and values of museums. However, in this paper, I argue that some of the very considerations museums appeal to in order to oppose repatriation claims can be turned on their heads and marshaled in favor of the practice. In addition to defending against objections to repatriation, this argument yields the surprising conclusion that the redistribution of cultural goods should be much more radical than is typically supposed.
\end{abstract}

\section{Introduction}

Museums are home to millions of artworks and cultural artifacts. The Metropolitan Museum of Art alone holds two million objects. The Hermitage has three million. The British Museum, eight million. Some of these objects have made their way to these institutions through unjust means. Some were stolen or plundered, others acquired through coerced or exploitative transactions. Should these injustices be rectified, and if so, how? Some argue that there are objects in museum collections that should be repatriated, returned to their country, culture, or owner of origin. For instance, consider claims for the return of the Benin Bronzes, pillaged from the Benin Kingdom during the British Punitive Expedition of 1897, or the abundance of claims for the return of Native American cultural items that led to the passage of the Native American Graves Protection and Repatriation Act in 1990. According to claims like these, museums have a moral obligation to repatriate questionably acquired objects from their collections.

Contact: Erich Hatala Matthes <ematthes@wellesley.edu> 
However, there is a substantial literature spanning philosophy, law, and anthropology that explores the moral complications of the repatriation proposal. Objections to repatriation can be divided into roughly three kinds. First, there are metaphysical challenges concerning the continuity of cultural groups over time, which pose problems for determining to whom objects should be repatriated. Second, there are epistemic challenges according to which limitations on our knowledge of the conditions under which objects were acquired render the justice of their acquisition unclear, potentially undermining the legitimacy of claims for repatriation. Finally, even if these first two challenges can be met, there are objections that question whether museums have an obligation to repatriate at all, especially given countervailing considerations concerning their institutional mission.

In this article, I attempt to avoid all three of these objections. I argue that the third objection can be met head-on, while the first two can be effectively sidestepped. I demonstrate this by arguing that a response to the historical injustices of illicit art and artifact acquisition can be fruitfully embedded in a broader concern with pursuing a just distribution of cultural goods. Beyond defending against objections to repatriation, this argument yields the surprising conclusion that the redistribution of cultural resources should be much more radical than is typically supposed.

The article will proceed as follows. I begin by briefly outlining some of the most significant objections that have been presented against claims for repatriation. Discussion of repatriation in general, and in the philosophical literature in particular, is typically framed in the context of two related issues: cultural property and reparations for historical injustices. I will address those two frameworks, and the objections that they generate, in Sections 2 and 3, illustrating the persistence of the three philosophical problems presented above. In Section 4, I introduce my argument in favor of embedding repatriation claims in a broader redistributive framework, and demonstrate how this approach avoids the objections raised in the previous sections. Section 5 concludes.

\section{Cultural Property}

Repatriation claims are typically made on behalf of groups rather than individuals. ${ }^{1}$ This seems to require some understanding of a group as the rightful owner or possessor of an object, and hence appeal to the concept of cultural property. As Janna Thompson writes, "Cultural property is the property of a collectivity"

1. The most common exception to this is Nazi-looted art, where repatriation is often sought on behalf of individuals (or families). 
(2003: 252). Or as Kwame Anthony Appiah puts it, the idea "is that, in the simplest terms, cultural property be regarded as the property of its culture" (2006: 118). As Thompson cautions, the etymology of repatriation aside, it's not clear that the relevant owners of cultural property should or must be states or other territorially bound collectives: a dispersed indigenous people, for instance, could be the rightful owners of cultural property (2003: 252). She suggests that, in a general sense, cultural property be understood as legitimately owned property that "plays an important role in the religious, cultural or political life of people of the collectivity" (Thompson 2003: 252). ${ }^{2}$

Thompson notes that her definition of cultural property places at least two limits on cultural property claims. First, "a collectivity cannot claim an artifact as its cultural property just because it was produced by its members. The item has to play an important role in its communal practices" (Thompson 2003: 253; cf. Young 2007: 115-119). Second, "the definition also presupposes that claims will be made by collectives that are capable of acting as agents-organised groups like states, tribes, or churches" (Thompson 2003: 253). These limitations reveal respects in which Thompson's definition of cultural property may be unduly narrow. With regard to the first limitation, it's not clear that production by a member of a culture cannot be construed as grounding at least certain moral claims that might fit in the bundle of property rights. ${ }^{3}$ For instance, production by a member of a particular culture might delineate moral restrictions on how that product is used or represented by cultural outsiders, especially in the context of appropriation of the product of a culturally marginalized group by members of a culturally dominant group (Matthes 2016). This would not necessarily require that the product play an important role in communal practices. ${ }^{4}$

With respect to the second limitation, even if we grant that the relevant collectives must be able to act as agents, this does not necessarily entail that the relevant groups must be organized groups or "structured wholes" (Ritchie 2015). ${ }^{5}$ If the relevant agential powers include, for instance, assertion and consent, recent philosophical scholarship suggests that informal groups could have such powers

2. The more closely the identity of a group is linked with a particular item of cultural property, the more likely those such as James Cuno might be to refer to it as "cultural patrimony," which he says "is not something owned by a people, but something of them, a part of their defining collective identity" (2001: 85). According to this line of thinking, the more important an item is to a cultural group, the more likely it is to pass beyond the category of property, cultural or otherwise, altogether (Cuno 2001: 85).

3. For a comprehensive look at how cultural property might involve rights for non-titleholders, see Carpenter, Katyal, and Riley (2009).

4. For further considerations in favor of a "cultural significance principle" for grounding cultural property claims, see Young $(2006 ; 2007)$.

5. Young also acknowledges that cultural property "does not require formal institutions," though he appears to think this will only be an option for very small groups (Young 2007: 112). 
as well, granted that the authority to speak for the group will be acquired by similarly informal means, such as lack of objection from other group members (Lackey 2017). This qualification could thus provide an avenue for addressing questions about who decides to where an item of cultural property should be repatriated, even where the group in question is informal, heterogeneous, and dispersed.

The possibility of informal cultural group action raises the difficult question of who counts as a member of a cultural group. ${ }^{6}$ As James Young puts it, "It does not make much sense to talk about a culture owning property unless the members of the culture can be identified" (2007: 112). The practical applicability of the concept of cultural property to repatriation issues in particular seems to require addressing questions about cultural group membership. The question is especially pressing in the context of cultural property claims meant to apply across long periods of time, and hence across apparent cultural discontinuities. As Appiah cautions,

When Nigerians claim a Nok sculpture as part of their patrimony, they are claiming for a nation whose boundaries are less than a century old, the works of a civilization more than two millennia ago, created by a people that no longer exists, and whose descendants we know nothing about. (2006: 119).

Although cultural property claims concerning nations have an inherently political dimension, it is striking that concerns about cultural discontinuity are often divorced from relevant features of the contemporary political context, as if the concept of cultural property ought to be applied universally, independently of facts about relative socio-political power. Appiah worries that the logic of cultural patrimony entails, for instance, that all Norse goblets should be returned to Norway (2006: 121). Observations such as these are often intended as a reductio of the concept of cultural property. While I am critical of the type of nationalist retention policies that such a reading of cultural property can be used to justify (for reasons discussed in Section 4), I am skeptical about the idea that the concept of cultural property requires the kind of uniform application that would entail the cited conclusion about (e.g.) Norse artifacts, especially at the level of nation-states. Indeed, it's revealing that Appiah pivots to an example concerning Norway in making this claim - the purported absurdity of returning all Norse goblets to Norway is, I would suggest, subtly premised on the fact that Norway has not been subject to the kind of colonialism that has prompted many claims for return of art and artifacts from other groups. 7 The mistake stems from thinking that claims about cul-

6. For discussion, see, for example: Matthes (2015; 2016), Narayan (1998), Patten (2014), Young (2008).

7. James Young helpfully notes that Norway was governed by both Denmark and Sweden at various points. While there are many examples of shifting sovereignty over nearby territories (as 
tural property must be justified by appeal to a universal understanding of cultural products as the property of the particular culture that birthed them, independently of facts about socio-political power. ${ }^{8}$ But advocates of cultural property need not be committed to such a principle, any more than an opponent of cultural appropriation must be committed to the claim that it is wrong for a Native American to wear blue jeans (Matthes 2016; Todd 1990). Consistency only requires treating like cases alike, and principles that abstract away from the morally differentiating features of a case are distractions rather than objections. ${ }^{9}$

While the brief considerations here suggest that the concept of cultural property cannot be too hastily dismissed, they do not provide a solution to the problem of cultural group membership. Indeed, that problem carries over to approaches to repatriation as a form of reparations for historical injustice, where additional challenges arise as well.

\section{Repatriation as Reparations}

A general argument for repatriation as a form of reparations can be framed as follows:

1) establish an obligation to correct an historical injustice,

2) establish an appropriate form of correction (viz., reparation),

3) establish an appropriate means of reparation (viz., repatriation). ${ }^{10}$

Objections can be raised at each stage of this general argumentative framework.

in the case of Scandinavia), colonialism as I understand it here is characterized by either settlement or large-scale extraction of resources from a foreign land. In either case, there is an accompanying cultural domination that occurs through processes of displacement, appropriation, extermination, slavery, or extraction, which I take it were exacerbated by the supposed cultural and racial superiority of European colonists. While I am sure that more local changes in sovereignty in Scandinavia had cultural consequences as well, given the relative cultural similarities of the Scandinavian countries, I do not think we're dealing with the same phenomenon that we see in European colonialism on other continents. For relevant discussion, see Kohn and Reddy (2017). For a similar contrast between Scandinavian nations and European colonialism of other continents in the context of museums and cultural heritage, see Atkinson (2014: 48).

8. Indeed, from a legal perspective, "cultural property is partially intended to repair the ruptures associated with a history of colonization and capture" (Carpenter et al. 2009: 1033). Moreover, the very concept of cultural property emerged largely in the context of thinking about the ethics of war, hardly an apolitical context for theorizing. For historical context, see Merryman (1986).

9. It of course remains possible that considerations of contemporary socio-political power should be regarded as irrelevant to our understanding of cultural property, but that conclusion should be argued for, not merely assumed in our understanding of the concept itself.

10. This framework is based on one provided in Björnberg (2014: 463). 


\subsection{Establishing Unjust Acquisition}

Karin Björnberg outlines three examples of ways in which the acquisition of a cultural artifact might be unjust: (1) illegal acquisitions (where immorality is inferred from illegality), (2) "improper agreement" (where the acquisition is prima facie consensual, but coerced or exploitative), and (3) third-party transfer by someone who is not the owner and thus does not have the moral right to transfer the artifact (Björnberg 2014: 464). An extension of Björnberg's third example would make appeal to the concept of cultural property: one might argue that an acquisition is unjust because the artifact is not subject to individual ownership by anyone, and thus cannot justly be transferred by any individual, including a person who belongs to the relevant culture (cf. Thompson 2003: 255). By introducing the concept of inalienable cultural property, the same claim could be applied to groups as a whole as well (Coleman 2010).

Björnberg suggests it will often be difficult to establish whether artifacts were acquired unjustly, in which case a specifically reparative claim for repatriation cannot be made (though she notes that this does not necessarily undermine other non-reparative arguments for repatriation) (2014: 464). The 1970 UNESCO Convention on the Means of Prohibiting and Preventing the Illicit Import, Export and Transfer of Ownership of Cultural Property established stricter guidelines for the documentation of archaeological finds and artifact acquisitions such that we can defeasibly infer that unprovenanced artifacts acquired after 1970 were unjustly acquired; however, this offers no help when it comes to determining the justice of acquisition for the millions of objects already in institutional collections prior to 1970 . So, substantial uncertainty often remains.

\subsection{Establishing the Appropriateness of Reparations}

If we grant that unjust acquisition can be established, and that unjust actions ought to be remedied, we are then faced with establishing that reparations per se are the appropriate form of remedy for addressing the historical injustice. This approach requires that we determine to whom reparations are owed.

If the individuals from whom artifacts were unjustly acquired are still alive, the answer to this question is straightforward. However, for cases involving unjust acquisition in the further past, we face a problem. If the former owners of unjustly acquired artifacts are deceased, then it seems reparations cannot be made to them. ${ }^{11}$ So, this fact can lead us to question whether reparations are the appropriate form of redress for the historical injustice, unless we can establish

11. Though some argue that reparations might be owed to the dead. For instance, see Ridge (2003).

Ergo vol. 4, no. $32 \cdot 2017$ 
that reparation to some other party will itself satisfy the obligation of redress. In other words, are there "moral descendants" of those who were originally wronged, to whom reparations would rectify the wrong in question? This way of posing the question leaves open whether the relevant descendants are biological descendants or cultural/political descendants.

Björnberg adapts two ways of understanding the "transfer of victimization" from Bernard Boxill's work on reparations for slavery in the U.S. (Björnberg 2014: 465; Boxill 2003). According to Boxill's "harm argument," past harms can initiate a chain of harms that continue to harm people today. So the unjust acquisition of artifacts not only harmed their owners at that time, but also initiated a chain of events that harms people in the present. According to Boxill's "inheritance argument," victims of historical injustice were owed reparations that they did not receive, and the right to be compensated is inherited by their descendants. So the unjust acquisition of artifacts should have been redressed in the past, and the right to have that past injustice remedied redounds to the descendants of the initial wrong.

According to Björnberg, both the harm argument and the inheritance argument require identifying the "legitimate descendants" of the original victims (2014: 465). ${ }^{12}$ While this is clearly a pressing task for advocates of the inheritance argument, its application to the harm argument is less straightforward. On at least one reading of the harm argument, the legitimate descendants of the original victims are identified by the fact that we can trace a present harm to the past harm in question, not the other way around. ${ }^{13}$ To be sure, it may still be difficult to adequately demonstrate the relevant causal chain of harm, so identifying the legitimate descendants may well still be difficult. But we should be clear that this approach reveals who the moral descendants of past victims are, rather than presupposing it.

With respect to identifying legitimate descendants for the purposes of the inheritance argument, Björnberg suggests that we can appeal to arguments about national self-determination that emphasize the bonds of common culture (2014: 466). However, this approach pushes us back onto the problem of cultural group membership. Looking to cultural continuity may well be a promising direction to take, but it leaves a substantial philosophical task to be addressed.

12. Björnberg also considers objections that apply only to the harm argument: the nonidentity objection and the counterfactual objection. As Björnberg notes, neither of these objections are particularly compelling in the context of cultural artifacts, so I will not discuss them here.

13. An alternative reading might suggest that we first identify the legitimate descendants, and we can then infer that they are therefore harmed by the very fact that they are the legitimate descendants. But this seems ad hoc and not in the spirit of the argument: there should be some identifiable harm that we can point to on this approach. Note that the inheritance argument is not likewise subject to this concern, because inheriting the right to reparation does not require also inheriting the harm of the original injustice. 


\subsection{Establishing Repatriation as the Appropriate Means of Reparation}

Assuming that reparations are indeed called for in response to an historical injustice, and the legitimate recipients of the reparations can be identified, it remains to be established that repatriation is the appropriate means of reparation. Given that our topic is the unjust acquisition of art and artifacts, the idea that repatriation is the appropriate means of reparation has significant intuitive appeal: stolen goods should be returned. Another common means of reparation is compensation, but this seems most appropriate in contexts where the original harm in question cannot otherwise be repaired (because, for instance, an item has been destroyed, or the harm was pain and suffering, or originally financial in nature). For instance, if someone steals my car, then they ought to give it back, not just compensate me for its monetary value: indeed, I could not justifiably demand compensation instead of return of the vehicle (Simmons 1995: 167). Art and artifacts in particular are often regarded as irreplaceable, and whether or not this is strictly true, they can certainly have a value that resists straightforward replacement with financial compensation (see Matthes 2013).

However, even if it is true that repatriation is the most appropriate means of reparation for the unjust acquisition of art and artifacts, some argue that these repatriation claims can be outweighed by competing considerations (Björnberg 2014: 472; Thompson 2003: 257; Young 2007: 122). These can range from claims about the supersession of historical injustice, to the prioritization of preservation, to the outstanding value of objects and their consequent interest to all of humanity. This latter point is a particularly common invocation made by proponents of institutional retention. As Thompson puts it, "The case for return can be more or less strong, and often an appeal to [universal] human values will favour the position of the museum directors" (2003: 261). The key point here is that repatriation is typically viewed as contrary to the interests of museums and other cultural institutions, especially with respect to their mission of serving the public interest. It is thus thought that repatriation claims must be quite strong in order to be decisive, strong enough to outweigh these significant competing considerations.

\section{Repatriation and the Just Distribution of Cultural Goods}

The forgoing overview of philosophical challenges for repatriation suggests the following three central issues must be addressed:

First, the legitimate descendants of historical injustices are often uncertain, due in part to worries about cultural continuity over time. If we cannot identify the individuals to whom reparations are legitimately owed, then we will not know to whom artworks and artifacts should be repatriated. 
Second, there will often be ambiguity surrounding the justice (or lack thereof) of artifact acquisition. If we are uncertain whether an object was unjustly acquired, then it will not be clear whether repatriation of the object is warranted.

Finally, even if these first two challenges can be addressed and a legitimate claim for repatriation established, some argue that these repatriation claims can be outweighed by competing considerations. In particular, it is often claimed that repatriation is contrary to the values and mission of museums and cultural institutions.

In what follows, I argue that all of these challenges can be met. In order to do this, I will briefly pivot away from direct discussion of repatriation in order to focus on the aims of museums and cultural institutions, and the purportedly universal human values that they endeavor to serve. I will use these aims to introduce considerations of distributive justice into our thinking about cultural goods, which in turn offers an opportunity for repatriation to reenter the picture. In the end, I submit we will have an argument in favor of the radical redistribution of cultural goods in which repatriation has an important role to play, and in which the major philosophical challenges identified above are addressed.

\subsection{Cultural Goods and Universal Values}

Museums and cultural institutions tend to embrace the idea, enshrined in the Hague Convention of 1954, that cultural products are contributions to the culture of all humankind. As the preamble to that text reads: "Damage to cultural property belonging to any people whatsoever means damage to the cultural heritage of all mankind, since each people makes its contribution to the culture of the world" (As quoted in Merryman 1986: 836). This sentiment is echoed in a 1982 UNESCO convention addressing artifacts and sites that are considered part of world heritage: "Their value cannot be confined to one nation or to one people, but is there to be shared by every man, woman and child of the globe" (As quoted in Omland 2006: 247). Such commitments concerning the universal value of cultural products are often marshaled against claims for repatriation. As Thompson puts it, "The argument advanced by those who think that museums are within their rights to resist restitution claims is that some artefacts are of such great value for humanity that it is justified to restrict or override rights of cultural property in order to promote or protect this value" (2003: 257). ${ }^{14}$

14. It is worth noting here that some might question the idea that cultural goods have the kind of universal humanistic value that museums claim, and upon which this argument is premised. However, in line with Thompson's comment, if we decided to give up on this premise, then one (if not the only) major institutional objection to repatriation claims disappears. So the result is a stronger argument for repatriation either way, albeit without the broader distributive framework in the latter case. 
However, despite often being pitted in favor of institutional retention, if we take seriously the claim that art and artifacts have a kind of universal value, then it seems that we need to think carefully about the just distribution of such cultural goods. After all, we typically think that "universal human values" are such that lack of access to them can constitute an injustice. As Thompson writes, "If we think of art as being of value for individual development and to humankind as a whole, then distributional issues cannot be avoided" (2004: 558-559). She is focused specifically on an argument against certain nationalist cultural retention policies, but the same point can serve as a stepping-stone toward broader reflection on the distribution of cultural goods. ${ }^{15}$

Principles of distributive justice are typically invoked in the context of goods that are held privately. For instance, insofar as systems of taxation are justified by principles of distributive justice, they bear on goods that are held privately, namely, individual wealth. Public goods, on the other hand, are not often regarded as subject to principles of distributive justice. In discussing this feature of the literature, David Miller notes, "one possible explanation is that since these goods are available equally to everyone, no issue of justice arises" (2004: 129). He explains that this line of argument does not pay sufficient attention to the fact that equally available goods may not be equally used or valued, but I want to pause on the feature of equal availability. Insofar as it is in the nature of public goods (whether or not such a designation is purely conventional ${ }^{16}$ ) to be equally available, principles of distributive justice will apply strongly to goods that are designated as public but whose access is, restricted, whether de facto or de jure.

It is clear that the major art museums of the West view themselves less as owners of private goods than as stewards of public goods. Although some may charge fees for entry, the museum does not have the right to exclude anyone from access. ${ }^{17}$ Moreover, it is also clear that these museums consider the public good of their collections in a cosmopolitan, as opposed to nationalist, light. For instance, in the "Declaration of the Importance and Value of Universal Museums," a group of museum leaders including the directors of the Met, the Getty, the Hermitage, and the British museum write, "Museums serve not just the citizens of one nation but the people of every nation."18 Indeed, some cultural orga-

15. This comes up again in Thompson (2010: 254-255). She suggests there that the idea of culture as "'the property of humanity' seems to weaken the hold over them of the possessing nation" (2010: 254-255). Yes and no. It might weaken the mere claim that given cultural properties should be possessed because that is the status quo, but, as she somewhat acknowledges in the next paragraph, what it really does is activate a positive consideration of distributive justice that might outweigh the status quo.

16. This is Miller's view. For a response, see Lindsay (2012).

17. In this sense, art and cultural resources are not "pure public goods," but qualify as public nonetheless. See Miller (2004: 128, Footnote 122).

18. "Declaration of the Importance and Value of Universal Museums" (2004). 
nizations have even construed access to these goods in terms of human rights. For instance, in a 2016 declaration, the United Nations Human Rights Council writes, "Convinced that damage to cultural heritage, both tangible and intangible, of any people constitutes damage to the cultural heritage of humanity as a whole; Noting that the destruction of or damage to cultural heritage may have a detrimental and irreversible impact on the enjoyment of cultural rights, in particular the right of everyone to take part in cultural life, including the ability to access and enjoy cultural heritage."19 Combining these two claims suggests a human right to a universal human heritage.

Data concerning the global distribution of art is surprisingly difficult to find. But facts about the locations of the world's largest museums, in concert with facts about the imperial origins of encyclopedic museums in general, strongly indicates that the distribution of global museum holdings is skewed significantly towards "Western" institutions. However, if the goods that museums hold are public goods with universal value, goods everyone may even have a human right to access and experience, then we need to ask whether the current distribution of these goods is just.

For the purposes of this discussion, I want to leave open the thorny question of what precise principles of justice might govern the distribution of cultural goods: this will depend largely on what the correct theory of distributive justice in general turns out to be. Suffice it to say that, given the radical inequality of the current global distribution of institutionally held cultural resources, most any reasonable principle would entail an extensive redistribution of these goods, emptying the vast storerooms of Western museums and sharing their resources around the world. ${ }^{20}$ But rather than address what precisely this distribution should look like, I want to focus here on the way in which repatriation might reenter the picture once the matter of a just distribution of cultural goods is on the table.

As suggested, the distribution of institutional cultural goods is skewed towards Western nations and cultural groups and away from others. ${ }^{21}$ But moreover, that distribution has a particular character. That Western museums have a long history of cultural marginalization should come as no surprise. Examples include the exclusion of non-Western artworks to anthropology museums as

19. United Nations (2016). Note that the language of the first clause echoes the language of the 1954 Hague Convention, quoted above.

20. I am assuming here that principles of distributive justice apply across borders, though the possibility of global distributive justice remains contentious in the literature. For an overview, see Brock (2017).

21. This should of course not be confused with a claim that suggests that non-Western nations are culturally impoverished: the focus here is on a particular kind of cultural good held by museums and like institutions. This is consistent with the obvious existence of rich cultural practices around the world. 
opposed to art museums, their designation as "primitive" within the artworld context, and, despite these aspersions on their artistic status, the colonialist acquisition of many such objects (Eaton \& Gaskell 2012; Nicholas \& Wylie 2013). So the current distribution of cultural resources is both a product and reflection of, among other things, cultural domination.

The unequal distribution of these cultural goods thus not only indicates the need for redistribution in light of museums' own values and commitments, but moreover, the character of the current distribution suggests that a fitting approach to redistribution should be sensitive where possible to how such an effort can aid in counteracting the social marginalization with which the current distribution is entangled (Glass 2004). In other words, we should thus consider how the redistribution of cultural resources can facilitate recognition for historically and currently marginalized groups. ${ }^{22}$

As has been argued in other contexts, achieving recognition in justice can require restorative justice, or reparation (Figueroa \& Waitt 2010). It is difficult to achieve recognition in an institutional system that is based on the systematic subordination of other cultures without an attempt to redress the historical roots of that system. However, the distributive inequities of cultural goods go beyond any specific instances of unjust acquisition we might identify. Institutional commitment to the universal value of cultural goods suggests that, whatever the just distribution of cultural goods ultimately is, the redistribution of those goods to cultural communities that have been historically marginalized with respect to their access to these goods will be much broader than just the return of certain looted or coercively acquired artifacts. Indeed, contrary to the cultural property narrative that associates repatriation with nationalism, strong cultural retention policies would be anathema to the broader patterns of distributive justice in cultural goods that we ought to endeavor to secure. ${ }^{23}$ For example, if paradigmatic

22. Nancy Fraser's work on recognition in justice is an important touchstone here. Fraser adopts a "status model" of recognition, according to which lack of recognition is a matter of institutionalized subordination rather than "an impediment to ethical self-realization," as philosophers such as Charles Taylor and Axel Honneth construe it. Thus, as she puts it, claims for recognition are a matter of justice that "aim ... to deinstitutionalize patterns of cultural value that impede parity of participation and to replace them with patterns that foster it" (Fraser \& Honneth 2003: 30). However, Fraser treats redistribution and recognition as related but distinct, to the extent that problems of maldistribution or misrecognition cannot "be redressed indirectly ... through remedies addressed exclusively to the other" (23). I leave aside here what further efforts might be required to achieve recognition of marginalized culture groups, but my argument supports the idea, in slight tension with Fraser, that indirect redress for misrecognition can, at least partially, be achieved through appropriate forms of redistribution.

23. It is important to remember that when museums and other institutions object to repatriation of art and artifacts based on the idea that these items belong to "all of humanity," they are not objecting to the concept of cultural property per se, but rather, objecting to the scope of its application in a particular context. Indeed, they are using the logic of cultural property to assert that a relevant bundle of rights over the artifacts in question belongs to everyone specifically in virtue of 
instances of Mexican or Egyptian art have universal human value, then extant policies that prohibit the export of these goods are also unjust, at least in this respect. ${ }^{24}$ This entails that not all plausible repatriation claims will ultimately be satisfied on this approach; however, as I will continue to argue, it provides some novel avenues for the return of objects as a component of achieving a just distribution. Given the current pattern in holdings, this approach promises an overwhelmingly different distribution of institutional cultural goods, even if not all objects are repatriated. ${ }^{25}$

Because redistribution should aim to correct both the regional and numerical inequity of the current distribution, as well as the colonial character of that distribution, a fitting solution cannot simply involve attempts to maximize access to institutional cultural goods based on population. While an adequate response to these twin problems will certainly increase global access to cultural goods on the whole (for instance, by redistributing Western collections to high-population former colonies in Asia and Africa), sometimes correcting the colonial character of the distribution will be at odds with purely maximizing access. For instance, intranational redistribution that facilitates access to indigenous artifacts for indigenous communities may often not increase access to those objects for larger populations in general. ${ }^{26}$ However, given that the processes that led to institutional holdings in indigenous artifacts are inseparable from the processes that decimated indigenous populations, the fact that improving access for indigenous people will not numerically increase access overall is expected, and not a weighty objection. Moreover, at the scale of cultural groups as opposed to pure population, such efforts could still increase access for culturally marginalized communities. ${ }^{27}$

So, to take stock of where we are so far: The current distribution of cultural goods is contrary to some of the explicit values of museums and cultural institu-

the shared culture of humanity (Merryman 1986: 831). Peter Lindsay claims, moreover, that both appeals are grounded in identity claims (Lindsay 2012).

24. Perhaps such policies have justification as a check on looting, but that is largely an empirical question.

25. I assume that repatriation will require ceding control over the relevant objects and that this is an essential element, along with increasing access, to achieving justice in recognition. However, I leave open the possibility that Western museums might in some cases maintain partnerships that would facilitate access and allow these institutions a continued role in actively pursuing their mission. I leave further reflection on the complicated matter of control for future work.

26. For relevant discussion concerning intranational cultural property issues and indigenous communities, see Watkins (2005). Moreover, repatriation of some indigenous artifacts will be flatly inconsistent with increasing access if the artifacts in question are intended for privileged access, or will subsequently be left to decay, such as the Zuni War God sculptures, as discussed in Young (2008: 98-99). However, I take it that such artifacts should clearly never have been subject to institutional control in the first place, and thus we might accept that meeting these culturally specific needs will be lexically prior to the institutional redistribution recommended here.

27. Thanks to Shen-yi Liao for pressing me on this point. 
tions. Indeed, the assignment of universal vale to these collections suggests that they should be subject to principles of global distributive justice. Moreover, the character of the current distribution of such goods, which is produced by and reflective of patterns of cultural marginalization, points to redistribution as a (at least partial) means of redressing this subordinated status. Independently of what specific principles of distribution ultimately ought to apply, these considerations together lend support to the idea that justice will require radical redistribution of cultural goods throughout the world, in part based on their value to humanity, but guided as well by the unjust history of their acquisition: this scheme will thus involve both de facto and de jure instances of repatriation. In practice, this will mean that access to representative collections of cultural goods from a wide array of cultural contexts be made available to a much broader population of cultural consumers around the world. ${ }^{28}$ In the next section, I will explain how the proposal avoids the persistent objections to repatriation presented above.

Although my proposal may seem extreme, it is striking to see that versions of it are latent in the work of some opponents of repatriation themselves, though to my knowledge, never fully developed. For instance, in Merryman's classic treatment of cultural property, he levies the universal value of cultural heritage in order to support an "internationalist" or "cosmopolitan" approach that criticizes nationalist policies of retention that inhibit the free flow of cultural resources around the world (Merryman 1986). However, as Rosemary Coombe has noted, Merryman seems less willing to credence the implications of such an approach when applied to major Western museums and holdings in cultural resources:

One suspects, however, that Merryman would likely object to the movement of Rembrandts from the Netherlands to Lagos, despite the fact that Rembrandt's paintings might be "over-represented" in their country of origin where they cannot possibly be put to their full use, that the Dutch "fail to spread their culture" to the Third World, and that they thereby "contribute to the cultural impoverishment of people" in Africa. The existence of vast and seldom displayed holdings in European and North American museums does not appear to have led to any movement amongst "cultural internationalists" to establish better museums in Nia-

28. One might ask why increasing access requires moving art rather than moving people. I take it that substantially increasing access to cultural goods while keeping those goods highly concentrated in their current locations is infeasible. One might also ask about whether access through digitization might meet the relevant aims. While I support open digital access to museum collections, the very resistance to redistribution of original objects themselves suggests that increasing access merely through digitization would be inadequate. For some discussion in the context of repatriation to indigenous communities, see Crouch (2010). 
mey, Lima, or Nanjing despite the vastly larger numbers of people whose "cultural impoverishment" might thereby be alleviated by exposure to the sublime. The "cosmopolitan" attitude Merryman espouses appears more Eurocentric than worldly, more monocultural than respectful of cultural difference, and less concerned with the purported "interests of all mankind" than with the interests of maintaining Western hegemony. (Coombe 1993: 161-162)

On a similar note, Young, who is skeptical about many grounds for repatriation claims, does argue in favor of an "access principle," according to which one relevant consideration in adjudicating cultural property claims will be how well possession facilitates access "to all those persons for whom it has value" (2008: 99). He writes,

It is worth noting, in the context of a mention of the access principle, that the basements of the museums of the world are full of undisplayed, unstudied, and unappreciated works of art. The Victoria and Albert Musuem, for example, houses the largest collection of Indian art outside of India, approximately 40,000 artifacts. Very few of these items are on display. Undisplayed items might be highly valued in another context. An artwork that languishes in the basement of the British Museum, might be a prized exhibit in Haida Gwaii or the Solomon Islands. (Young 2008: 99-100)

These reflections are in principle friendly to my argument here, though as I have noted and will continue to argue, I believe that when embedded in consideration of the just distribution of cultural resources they have much more extensive implications than Young seems to think.

Björnberg, in her reparations-based discussion of repatriation, notes that other frameworks besides that of reparations need more attention including "the argument that, for utilitarian reasons, valuable cultural artefacts ought to be more justly distributed among the world's nations" (2014: 473). ${ }^{29}$ Even philosophers such as Appiah, who are critical of nationalist repatriation efforts, seem in principle friendly to this proposal. "I'd rather that we negotiated as restitution not just the major objects of significance for our history, things that make the best sense in the palace museum at Manhyia, but a decent collection of art from around the world" (Appiah 2006: 133).30 So, although my proposal may seem

29. My argument is of course not utilitarian, and bears a relationship to issues of reparation, as opposed to functioning as an independent alternative.

30. The idea that this proposal presents a "sort of synthesis of the call for culture-specific reclamation and the push towards immersion in the many cultures of the world" is also identified 
outlandish at first glance, it is important to see that the seeds of the idea are planted even among some of repatriation's opponents and skeptics.

One might worry that redistributing cultural goods in this manner will be inconsistent with other museum values, such as preservation, based on the concern that other less affluent nations may not be in a good position to care for these resources (Young 2008: 99). While this will sometimes be a relevant consideration, museums are always faced with balancing preservation with access, so it is at least not a new problem. Moreover, such arguments have historically been used to justify the acquisition of cultural goods based on particular Western notions of what cultural preservation requires. ${ }^{31}$ Finally, Western storage facilities are not always as ideal as one might assume. For instance, they can be inadequate in size and condition. ${ }^{32}$ They can also be subject to threats such as war and extreme weather. ${ }^{33}$ So while considerations of preservation should provide a check on redistributive schemes, and the selection of future collection sites should be sensitive to the preservation of objects, we should be wary of overplaying worries about preservation as a decisive objection to this proposal. The fact that redistribution of cultural goods might not be immediately possible due to current practical limitations does not undermine its normative significance as a future goal.

\subsection{Redistribution, Repatriation, and Particularized Shares}

Hopefully, it is already clear that the proposal I have argued for avoids the third major philosophical challenge to repatriation that I identified above. It demonstrates that repatriation is not inconsistent with museum values concerning the stewardship of public goods for the sake of an international audience; on the contrary, combined with considerations of justice, institutional commitments concerning the universal value of cultural goods entail a much more radical redistribution than even repatriation claims alone would warrant. I now want to argue that this proposal also allows us to avoid the other two lingering philosophical challenges for repatriation: ambiguity concerning the justice of acquisition, and uncertainty concerning cultural continuity.

I take it as granted that in cases where cultural goods were clearly unjustly acquired, repatriation to groups that are clearly continuous with the original vic-

in Jeffers (2013: 509).

31. For relevant discussion see Kersel (2016), Warren (1989), Wylie (2005).

32. For discussion in the context of archaeological collections, see Kersel (2015). Kersel documents some examples of the redistribution and deacessioning of over-taxed collections that are friendly to the theoretical argument I offer her.

33. Significant portions of the Smithsonian collections were moved during World War II out of fear that Washington would be targeted. See Smithsonian Institution Archives (n.d.). 
tims of the unjust acquisition will be required. This should be evident simply on the basis of common norms of reparative justice, though embedding them within the broader context of the redistribution of cultural goods reveals another way in which they are consistent with the evaluative commitments of museums. ${ }^{34}$ Given that some artworks and cultural artifacts are rare or unique, it is appropriate that those who were deprived of such objects via unjust means should have them returned in the process of broader redistribution. Clearly, the return of all objects that might be construed as the cultural property of a particular group will be inconsistent with the broader distributive aims of the approach that I am advocating (as mentioned above with respect to nationalist retention policies). But this does not mean that a just redistribution should be insensitive to the historical facts about how the current distribution came about. As A. John Simmons notes in discussing the historical rights of Native Americans to unjustly seized lands,

Their rights are not, I think, just rights to some fair share of American resources; they are rights to a particular (or a particularized) fair share. Treating Native American rights as exclusively end-state rights means denying that the actual arguments made by Native American tribes for historical rights to particular lands and resources have any moral force at all, or any appeal beyond ungrounded emotionalism. (1995: 174)

The notion of a "particularized share" is important. Simmons defines a particularized share as "a right to a certain-sized share of a particular set of holdingsnamely, to a share of the holdings of the wrongdoer" (Simmons 1995: 162). He notes that the notion of a particularized share can be invoked in contexts where a stolen item has been destroyed, or when even legitimate holdings are "downsized." But of most relevance for our purposes, Simmons points to the power of this notion for contexts of rectifying injustice under conditions of uncertainty:

The theory also gives us some reason to believe that the problem of rectifying complicated injustices may not be insoluble in principle. For even if we cannot say precisely to what particular thing some individual or group is entitled, we can now see that just rectification may be achieved in such a case by redistribution within a range of appropriate outcomes. (Simmons 1995: 166)

This approach thus gives us the resources to address repatriation issues under contexts of uncertainty regarding the just acquisition of artifacts.

34. It is worth noting that even when these conditions are met, museums sometimes resist return of stolen items, claiming ignorance. See Bennett (2017). 
For example, many artifacts (and human remains) were looted from Native American burials and communities, and thus lack a well-documented provenance (Harjo 1996). Despite knowledge of this history, this very lack of documentation can generate uncertainty about the nature of the acquisition, and thus introduce the possibility that it was purchased or licitly discovered. Even if there is documentation that suggests a lawful sale, the just acquisition of the item in question may still be regarded as ambiguous. On the one hand, we may want to acknowledge the possibility of autonomous agency even under the yoke of colonialism. On the other hand, we may worry that the colonial power dynamics in the transaction have undermined the legitimacy of the acquisition (Björnberg 2014: 464; Coleman, Coombe, \& MacArailt 2012: 199; Walsh \& Lopes 2012: 226 227). Simmons's notion of a particularized share allows us to sidestep the uncertainty in such cases. Given the known injustices (and of particular salience here, cultural injustices) carried out against Native Americans by colonists, we can claim that a particular group, say, is entitled to a particularized share of museum holdings that includes items of the relevant type, even if a specific item cannot with certainty be identified as one to which they have a claim. While this does not guarantee the return of this particular artifact, it does guarantee the return of a particularized share of artifacts, which may well include this one in the end. This is a far superior way of navigating uncertainty about the just acquisition of artifacts relative to contemporary practice, which tends to just default to the status quo. Merryman, who argues that the burden of proof is on the claimant to establish unjust acquisition, a commitment enshrined in the U.S.'s 1990 Native American Graves Protection and Repatriation Act, explicitly advocates such a "principle of repose" (Harding 1997: 732).

As this example indicates, the approach that I argue for here will have particular appeal for repatriation claims set against the backdrop of colonial and imperial relationships. Given the role that these processes played in the establishment of Western museums, it will thus cover many relevant cases. It will consequently have less to say about, for instance, a claim for repatriation from another Western nation where the justice of acquisition is unclear. This is in keeping with my broader conclusion that the concept of cultural property is best understood as a political notion set against a backdrop of historical injustice, and my opposition to nationalist retention policies as inconsistent with a just distribution of cultural goods.

This approach also dovetails nicely with Lea Ypi's (2013) recent work on the wrong of colonialism. Ypi argues that the wrong of colonialism is best explained by "the creation and upholding of a political association that denies its members equal and reciprocal terms of cooperation," rather than by reference to nationalism or appeals to territorial rights (2013: 158). Thus the pursuit of recognition in response to such historical injustices may require the repatriation of some 
objects independently of the strength of claims to particular items. As she puts it, we might return certain items or access to lands

because in some cases the best way to make amends for our past wrongful behavior is to grant people what they want, regardless of why they want it and even if what they want is not something they may have been entitled to in the first place. (Ypi 2013: 187) 35

I am less skeptical about claims to territorial rights than Ypi, but paired with Simmons's understanding of particularized shares, we see here further support for the idea of repatriation justified by the pursuit of recognition within a redistributive scheme, even in the face of uncertainty regarding just acquisition concerning particular artifacts.

We can now turn to the problem of cultural continuity. First, it is important to note that the problem of cultural continuity is unlikely to arise for any repatriation claim that is based on a fairly recent unjust acquisition, rather than grounded solely in applying a nationalist conception of cultural property. For instance, Egyptian claims for the bust of Nefertiti, acquired by Germany in the early $20^{\text {th }}$ century, do not require demonstrating cultural continuity with Ancient Egyptians if the claim concerns unjust acquisition rather than a nationalist cultural property claim (Björnberg 2014: 466).

Second, the broad redistribution of cultural goods has the happy consequence of increasing access to a diverse array of cultural goods for a wide set of groups, regardless of how we sort out more difficult questions concerning cultural continuity. Moreover, worries about cultural continuity are typically marshaled in order to support maintaining the status quo distribution. ${ }^{36}$ Since the status quo will be upended on the approach I advocate, and it is not tied to nationalist conceptions of cultural property, it is not clear that the question of cultural continuity remains relevant: there will be de facto repatriation (of many, though necessarily, not all objects) through redistribution, independently of the need to establish strong links of cultural continuity where such relationships might be uncertain.

Finally, there are some cases where cultural continuity will continue to be relevant, but the notion of a particularized share may again be used as a conceptual resource. For instance, there are Native American repatriation cases where the claim is challenged because it is purported that the relevant cultural group no longer exists and lacks continuity with contemporary groups. 37 However,

35. For a similar point, see Harding (1997: 739).

36. For an extended defense of the status quo, see Jenkins (2016).

37. The most infamous case is no doubt that of "The Ancient One" or "Kennewick Man," though this case concerns human remains rather than artifacts. For a brief overview, see TallBear 
given the relationship between colonialism and the eradication of Native American cultural groups, we might advocate for the return of artifacts to a "particularized" cultural group (e.g., another tribe), even if the particular source culture is claimed to no longer exist.

\section{Conclusion}

I have argued that the three persistent challenges to repatriation can be avoided by embedding claims for repatriation in a broader framework concerning justice in cultural goods. Rather than thinking that the aims and values of museums are contrary to repatriation claims, I have argued that, coupled with principles of distributive justice, they actually entail the need for repatriation as part of a wide redistribution of cultural goods. Moreover, I have also highlighted how this approach avoids undesirable nationalist retention policies, which are often thought to follow from repatriation claims derived from appeal to the concept of cultural property. Museums and cultural institutions have the power to take substantial steps in pursuit of justice in cultural goods. If my argument is correct, then they ought to exercise that power.

\section{Acknowledgments}

Thanks to members of the Bard College philosophy and art history departments for excellent feedback on an earlier draft of this paper, and to Helena de Bres for thoughtful written comments. Thanks as well to James Young and Shen-yi Liao for helpful suggestions during the review process (not to mention for the bravery of signing their reviews), and to the editorial staff at Ergo. Thanks always to Jackie Hatala Matthes.

\section{References}

Appiah, Kwame Anthony (2006). Whose Culture Is It, Anyway? In Cosmopolitanism (113135). W. W. Norton.

Atkinson, Jeanette (2014). Education, Values and Ethics in International Heritage: Learning to Respect Routledge.

Bennett, Macaela J. (2017, January 12). Withers Attorney Analyzes New York Antiquities Scandal. Stamford Advocate. Retrieved from http://www.stamfordadvocate.com/business/article/Withers-attorney-analyzes-New-York-antiquities-10853688.php

(2015). For a more in-depth discussion of relevant issues, see TallBear (2013). Also Wilcox (2010). 
Björnberg, Karin Edvardsson (2014). Historic Injustices and the Moral Case for Cultural Repatriation. Ethical Theory and Moral Practice, 18(3), 461-474. https://doi.org/10.1007/ s10677-014-9530-z

Boxill, Bernard R. (2003). A Lockean Argument for Black Reparations. The Journal of Ethics, 7(1), 63-91. https://doi.org/10.1023/A:1022826929393

Brock, Gillian. (2017). Global Justice. In Edward N. Zalta (Ed.), Stanford Encyclopedia of Philosophy (Spring 2017 ed.). Retrieved from https://plato.stanford.edu/archives/ spr2017/entries/justice-global/. https://doi.org/10.1093/hepl/9780199680436.003.0010

Butt, Daniel (2009). Rectifying International Injustice. Oxford University Press.

Carpenter, Kristen A., Sonia K. Katyal, and Angela R. Riley (2009). In Defense of Property. The Yale Law Journal, 118(6), 1022-1125.

Coleman, Elizabeth (2010). Repatriation and the Concept of Inalienable Possession. In Paul Turnbull and Michael Pickering (Eds.), The Long Way Home (82-95). Berghan Books.

Coleman, Elizabeth Burns, Rosemary J. Coombe, and Fiona MacArailt (2012). A Broken Record: Subjecting 'Music' to Cultural Rights. In James O. Young and Conrad G. Brunk (Eds.), The Ethics of Cultural Appropriation (173-210). Blackwell.

Coombe, Rosemary J. (1993). The Properties of Culture and the Politics of Possessing Identity: Native Claims in the Cultural Appropriation Controversy. Canadian Journal of Law and Jurisprudence, 6(2), 249-285. https://doi.org/10.1017/S0841820900001922

Crouch, Michelle (2010). Digitization as Repatriation. Journal of Information Ethics, 19(1), 45-56. https://doi.org/10.3172/JIE.19.1.45

Cuno, James (2001). Museums and the Acquisition of Antiquities. Cardozo Arts E Entertainment Law Journal, 19(1), 83-96.

Declaration of the Importance and Value of Universal Museums (2004). ICOM News Magazine, 57(2), 4. Retrieved from http://icom.museum/fileadmin/user_upload/pdf/ ICOM_News/2004-1/ENG/p4_2004-1.pdf

Eaton, A. W. and Ivan Gaskell (2012). Do Subaltern Artifacts Belong in Art Museums? In James O. Young and Conrad G. Brunk (Eds.), The Ethics of Cultural Appropriation (235-267). Blackwell.

Figueroa, Robert Melchior, \& Gordon Waitt (2010). Climb: Restorative Justice, Enviromental Heritage, and the Moral Terrains of Uluru-Kata Tjuta National Park. Environmental Philosophy, 7(2), 135-163. https://doi.org/10.5840/envirophil20107219

Fraser, Nancy and Axel Honneth (2003). Redistribution or Recognition? A PoliticalPhilosophical Exchange. Verso.

Glass, Aaron (2004). Return to Sender: On the Politics of Cultural Property and the Proper Address of Art. Journal of Material Culture, 9(2), 115-139. https://doi. org/10.1177/1359183504044368

Harding, Sarah (1997). Justifying Repatriation of Native American Cultural Property. Indiana Law Journal, 72(3), 723-774.

Harjo, Suzan Shown (1996). Introduction. In Barbara Meister (Ed.), Mending the Circle: A Native American Repatriation Guide (3-7). American Indian Ritual Object Repatriation Foundation.

Jeffers, Chike (2013). Appiah's Cosmopolitanism. The Southern Journal of Philosophy, $51(4)$, 488-510. https://doi.org/10.1111/sjp.12040

Jenkins, Tiffany (2016). Keeping Their Marbles. Oxford University Press.

Kersel, Morag M. (2015). Storage Wars: Solving the Archaeological Curation Crisis? Journal of Eastern Mediterranean Archaeology and Heritage Studies, 3(1), 42-54. 
Kersel, Morag M. (2016). Acquisition Apologetics: A Case for Saving the Past for the Future? Brown Journal of World Affairs, 23(1), 109-126. https://doi.org/10.5325/jeasmedarcherstu.3.1.0042

Kohn, Margaret and Kavita Reddy. (2017). Colonialism. In Edward N. Zalta (Ed.), The Stanford Encylopedia of Philosophy (Fall 2017 ed.). Retrieved from https://plato.stanford.edu/archives/fall2017/entries/colonialism/

Lackey, Jennifer (2017). Group Assertion. Erkenntnis. Advance online Publication. https:// doi.org/10.1007/s10670-016-9870-2

Lindsay, Peter (2012). Can We Own the Past? Cultural Artifacts as Public Goods. Critical Review of International Social and Political Philosophy, 15(1), 1-17. https://doi.org/10.10 80/13698230.2011.583533

Matthes, Erich Hatala (2013). History, Value, and Irreplaceability. Ethics, 124(1), 35-64. https://doi.org/10.1086/671389

Matthes, Erich Hatala (2015). Impersonal Value, Universal Value, and the Scope of Cultural Heritage. Ethics, 125(4), 999-1027. https://doi.org/10.1086/680908

Matthes, Erich Hatala (2016). Cultural Appropriation Without Cultural Essentialism? Social Theory and Practice, 42(2), 343-366. https://doi.org/10.5840/soctheorpract201642219

Merryman, John Henry (1986). Two Ways of Thinking About Cultural Property. The American Journal of International Law, 8o(4), 831-853. https://doi.org/10.2307/2202065

Miller, David (2004). Justice, Democracy and Public Goods. In Keith Dowding, Robert E. Goodin, and Carole Pateman (Eds.), Justice and Democracy: Essays for Brian Barry (127-149). Cambridge University Press.

Narayan, Uma (1998). Essence of Culture and a Sense of History: A Feminist Critique of Cultural Essentialism. Hypatia, 13(2), 86-106. https://doi.org/10.1111/j.1527-2001.1998. tb01227.x

Nicholas, George P. and Alison Wylie (2013). “Do Not Do unto Others ..." Cultural Misrecognition and the Harms of Appropriation in an Open-Source World. In Geoffrey Scarre and Robin Coningham (Eds.), Appropriating the Past (195-221). Cambridge University Press.

Omland, Atle (2006). The Ethics of the World Heritage Concept. In Chris Scarre and Geoffrey Scarre (Eds.), The Ethics of Archaeology: Philosophical Perspectives on Archaeological Practice (242-259). Cambridge University Press. https://doi.org/10.1017/ CBO9780511817656.014

Patten, Alan (2014). Equal Recognition: The Moral Foundations of Minority Rights. Princeton University Press. https://doi.org/10.1515/9781400850433

Ridge, Michael (2003). Giving the Dead Their Due. Ethics, 114(1), 38-59. https://doi. org/10.1086/376717

Ritchie, Katherine (2015). The Metaphysics of Social Groups. Philosophy Compass, 10(5), 310-321. https://doi.org/10.1111/phc3.12213

Sher, George (1980). Ancient Wrongs and Modern Rights. Philosophy \& Public Affairs, $10(1), 3-17$.

Simmons, A. John (1995). Historical Rights and Fair Shares. Law and Philosophy, 14(2), 149-184. https://doi.org/10.1007/BF01001042

Smithsonian Institution Archives (n.d.). Smithsonian in Wartime. Retrieved from https:// siarchives.si.edu/history/exhibits/wartime/wwii-smithsonian-home-front\#c1

TallBear, Kim (2013). Native American DNA. University of Minnesota Press. 
TallBear, Kim (2015, July 23). Who Owns the Ancient One? Buzzfeed. Retrieved from https://www.buzzfeed.com/kimtallbear/how-the-man-stole-ancient-man-from-hisnative-descendents?utm_term=.ovOeWJmJN5 - .fbzO0nmnoR

Thompson, Janna (2001). Historical Injustice and Reparation: Justifying Claims of Descendants. Ethics, 112(1), 114-135. https://doi.org/10.1086/339139

Thompson, Janna (2003). Cultural Property, Restitution and Value. Journal of Applied Philosophy, 2o(3), 251-262. https://doi.org/10.1046/j.0264-3758.2003.00251.x

Thompson, Janna (2004). Art, Property Rights, and the Interests of Humanity. The Journal of Value Inquiry, 38(4), 545-6oo. https://doi.org/10.1007/s10790-005-5869-7

Thompson, Janna (2010). War and the Protection of Property. In Igor Primoratz (Ed.), Civilian Immunity in War (239-256). Oxford University Press.

Todd, Loretta (1990). Notes on Appropriation. Parallelogramme, 16(1), 24-33.

United Nations, Human Rigths Council (2016, September 30). Cultural Rights and the Protection of Cultural Hertiage (33/20). Retrieved from http://www.ohchr.org/EN/HRBodies/HRC/RegularSessions/Session33/Pages/ResDecStat.aspx.

Walsh, Andrea N. and Dominic McIver Lopes (2012). Objects of Appropriation. In James O. Young and Conrad G. Brunk (Eds.), The Ethics of Cultural Appropriation (211-234). Blackwell.

Warren, Karen J. (1989). A Philosophical Perspective on the Ethics and Resolution of Cultural Property Issues. In Phyllis Mauch Messenger (Ed.), The Ethics of Collecting Cultural Property (1-25). University of New Mexico Press.

Watkins, Joe (2005). Cultural Nationalists, Internationalists, and "Intra-Nationalists": Who's Right and Whose Right? International Journal of Cultural Property, 12(1), 78-94.

Wilcox, Michael (2010). NAGPRA and Indigenous Peoples: The Social Context, Controversies, and the Transformation of American Archaeology. In Wendy Ashmore, Dorothy Lippert, and Barbara J. Mills (Eds.), Voices in American Archaeology (178192). Society for American Archaeology.

Wylie, Alison (2005). The Promise and Perils of an Ethic of Stewardship. In Lynn Meskell and Peter Pels (Eds.), Embedding Ethics (47-68). Berg.

Young, James O. (2006). Cultures and the Ownership of Archaeological Finds. In Chris Scarre and Geoffrey Scarre (Eds.), The Ethics of Archaeology (15-31). Cambridge University Press. https://doi.org/10.1017/CBO9780511817656.002

Young, James O. (2007). Cultures and Cultural Property. Journal of Applied Philosophy, 24(2), 111-123. https://doi.org/10.1111/j.1468-5930.2007.00359.x

Young, James O. (2008). Cultural Appropriation in the Arts. Blackwell. https://doi. org/10.1002/9780470694190

Ypi, Lea (2013). What's Wrong with Colonialism. Philosophy \& Public Affairs, 41(2), 158191. https://doi.org/10.1111/papa.12014 
